\section{STRUCTURE OF ENZYMATICALLY ACETYLATED SISOMICIN \\ BY PSEUDOMONAS AERUGINOSA}

Sir :

As described in the previous paper ${ }^{1)}$, most Pseudomonas aeruginosa strains isolated from clinical specimens are sensitive to sisomicin (SS) but we found three SS-resistant (to $50 \mu \mathrm{g}$ $/ \mathrm{ml}$ or more) strains of $P$. aeruginosa GN269, GN315 and GN362 among our stock cultures. It was also found that these strains could inactivate SS by acetylation, although the position of acetylation was not clear ${ }^{1)}$. P. aeruginosa GN269 showed the greatest resistance against SS and was used in this experiment.

The strain was cultured in 3 liters of nutrient broth with shaking at $37^{\circ} \mathrm{C}$. The cells at the logarithmically growing phase $\left(\mathrm{OD}_{600 \mathrm{~nm}}\right.$, $0.6)$ were harvested by centrifugation, washed three times with TMK solution $(0.06 \mathrm{M} \mathrm{KCl}$, $0.01 \mathrm{~m}$ magnesium acetate and $0.006 \mathrm{~m} 2$-mercaptoethanol in $0.1 \mathrm{M}$ tris- $\mathrm{HCl}$ buffer, $\mathrm{pH} 7.8$ ) and suspended in $18 \mathrm{ml}$ of the same solution. The cell suspension was disrupted by a supersonic apparatus (Ohtake Co., Tokyo) at 20Kc for 10 minutes and centrifuged at $105,000 \times g$ for 2 hours to remove disrupted cell particles. The supernatant thus obtained was diluted with TMK solution to $20 \mathrm{mg}$ protein $/ \mathrm{ml}^{2)}$ and used as the S-105 fraction (crude extract).

The inactivation reaction was carried out by the method reported previously. ${ }^{1}$ SS was treated with the crude extract of GN269 strain at $37^{\circ} \mathrm{C}$ for 48 hours in a reaction mixture consisting of $30 \mathrm{ml}$ of the $\mathrm{S}-105$ fraction, $200 \mathrm{mg}$ of disodium ATP neutralized with $\mathrm{NaHCO}_{3}$, $20 \mathrm{mg}$ of $\mathrm{CoA}, 100 \mathrm{mg}$ of magnesium acetate and $50 \mathrm{mg}$ of SS. The reaction was stopped by heating at $100^{\circ} \mathrm{C}$ for 5 minutes and the residual antibiotic activity in the reaction mixture was bioassayed with Bacillus subtilis PCI-219 as the test organism. It was found that SS was completely inactivated.

The mixture containing the inactivated SS was centrifuged at $10,000 \times g$ for 30 minutes; the supernatant was adjusted to $\mathrm{pH} 4.5$ with sulfuric acid and the inactivated SS-sulfate was precipitated by addition of excessive ethanol. The precipitate was resuspended in redistilled water and excess ethanol was added to the solution. The same procedure was repeated
3 times. The precipitate thus obtained was dissolved in $5 \mathrm{ml}$ of redistilled water and the solution was passed through a Sephadex G-25 column $\left(1.8 \times 32 \mathrm{~cm}^{2}\right)$, those fractions $(10 \mathrm{ml})$ which showed both positive ninhydrin reaction $(0.2 \%$ ninhydrin in $n$-butanol saturated with water) and reactivation of the inactivated $\mathrm{SS}^{3)}$ by treatment with $2 \mathrm{~N} \mathrm{NaOH}$ (final concentration) at $100^{\circ} \mathrm{C}$ for 1 hour, was mixed and lyophilized. The yellow powder thus obtained was dissolved in $2 \mathrm{ml}$ of redistilled water, and the solution was passed through a Dowex 1 $\times 2$ column $\left(1.7 \times 34 \mathrm{~cm}^{2}, \mathrm{OH}^{-}\right.$form). Paper chromatography and thin-layer chromatography were carried out on each 5 -ml fraction. Fractions 6 and 7 showed a single spot by ninhydrin spray on paper chromatography and were mixed and lyophilized, yielding $4.1 \mathrm{mg}$ of white powder. The calculated value from the reactivation test was $4.5 \mathrm{mg}$.

In paper chromatography (Toyo filter paper No. 50) using the following solvent systems; $n$-butanol - pyridine - water - acetic acid $(6: 4$ $: 3: 1)$, I, and chloroform-methanol-28\% $\mathrm{NH}_{4} \mathrm{OH}(1: 1: 1)$, II, Rf values of SS and the inactivated SS were 0.05 and 0.12 with solvent I, and 0.40 and 0.55 with solvent II. In thinlayer chromatography (silica gel, Tokyo Kasei Co., Ltd.) using the following solvent system; chloroform - methanol-28\% $\mathrm{NH}_{4} \mathrm{OH} \quad(2: 1: 1)$, $\mathrm{Rf}$ values of SS and the inactivated SS were 0.25 and 0.32 , respectively. The chromatogram was developed by the ascending technique and visualized with either $0.2 \%$ ninhydrin or $50 \%$ sulfuric acid. The color of SS and the inactivated SS were yellow and violet during the early stages of heating $\left(120^{\circ} \mathrm{C}, 3\right.$ minutes $)$, respectively.

When the solution containing ${ }^{14} \mathrm{C}$-acetylated SS was used, the counts per minute of labeled acetate were recorded by Aloka paper scanner TRM-1 type. The $\mathrm{Rf}$ value of the incorporated ${ }^{14} \mathrm{C}$-acetate into SS $\left({ }^{14} \mathrm{C}\right.$-acetylated $\mathrm{SS})$ in the reaction mixture was 0.11 with solvent I. Chromatographic behavior of the ${ }^{14} \mathrm{C}$-acetylated SS, extracted with $1 \mathrm{M} \mathrm{NaCl}$ from phosphocellulose paper P-81, showed the same Rf value of 0.12 with solvent $\mathrm{I}$.

The inactivated SS melts at $197 \sim 200^{\circ} \mathrm{C}$ with bubbling compared to a melting point of $198 \sim$ $203^{\circ} \mathrm{C}$ for SS, and $191^{\circ} \mathrm{C}$ for gentamicin mixture. The infrared spectrum (Hitachi grating 
infrared spectrophotometer EPI-G3) of the inactivated SS showed amide bands I and II at $1640 \mathrm{~cm}^{-1}$ and $1570 \mathrm{~cm}^{-1}$.

The mass spectra of inactivated SS and SS were compared with some key features of the mass spectral fragmentation patterns of aminocyclitol antibiotics presented by DANIELS et al. ${ }^{4)}$, Cooper et al. ${ }^{5,6,7)}$ and INOuye. ${ }^{8)}$ The mass spectrum exhibited a molecular ion at $m / e 489$ and a somewhat more intense $(\mathrm{M}+1)^{+}$ at $m / e 490$ consistent with a mono-N-acetylated SS. Intense peaks at $m / e$ 191, 173, 163, 145 , and 160 could be attributed to the 2deoxystreptamine and garosamine ions (COOPER et al. ${ }^{6,7)}$ ), indicating that the acetyl group was not attached to either of these parts of the molecule. A prominent peak observed in SS at $m / e 127$ associated with $4^{\prime}, 5^{\prime}$-didehydropurpurosamine unit, ${ }^{4)}$ was absent from the spectrum of the acetylated compound. However, there was a peak in the inactivated SS at $m / e 169$, indicating that the $4^{\prime}, 5^{\prime}$-didehydropurpurosamine moiety was acetylated. Mass spectra were determined on a Hitachi double focusing mass spectrometer RMU-7L using a direct inlet system.

The nuclear magnetic resonance (nmr) spectra of the inactivated SS (base and sulfate) were compared with that of SS (base and sulfate). The inactivated SS sulfate was prepared from the base by adjustment to $\mathrm{pH}$ 4.5 with sulfuric acid. The nmr spectrum of SS was studied comparing with those of gentamicin $\mathrm{C}_{1 \mathrm{a}}$, gentamicin- $\mathrm{C}_{1}$, kanamycin and $6^{\prime}-\mathrm{N}$-acetylated kanamycin prepared by the crude enzyme of $P$. aeruginosa GN315. ${ }^{\circ)}$ The $\mathrm{nmr}$ spectra were determined on a Model JMN-4H-100 spectrometer (Japan Electron Optics Lab. Co., Ltd.) at $100 \mathrm{MHz}$ in deuterium oxide $\left(\mathrm{D}_{2} \mathrm{O}\right)$ solution using sodium trimethylsilane as the internal reference $(\sigma=0)$ or tetramethylsilane as the external reference. In the $\mathrm{nmr}$ spectrum of the inactivated SS-base in $\mathrm{D}_{2} \mathrm{O}$, the signal of the $\mathrm{C}-6^{\prime}$ methylene protons at $\sigma=3.52$ in SS-base shifted to $\sigma=3.73$, and sulfate showed a methyl proton signal from the acetyl group at $\sigma=2.13$. Thus, the structure of the inactivated SS was concluded to be $6^{\prime}-\mathrm{N}$-acetylsisomicin.

\section{Acknowledgement}

The authors wish to express deepest apprecia- tion to Dr. M. J. Weinstein, the Schering Corp., U.S.A. for a supply of sisomicin. We thank Dr. Y. Yamada, Mr. Y. Shida, Dr. K. OKa and Mr. H. Kinoshita, Laboratories of Chemistry and Pharmachemistry, Tokyo College of Pharmacy, for spectral determinations (mass and $\mathrm{nmr}$ spectrometers). We wish to thank $H$. Umezawa and S. Kondo, Institute of Microbial Chemistry, Tokyo for their helpful advices in carrying out these experiments.

\section{KoJi O'HARA \\ Megumi Kono \\ Susumu Mitsuhashi*}

Department of Microbiology,

Tokyo College of Pharmacy, Tokyo

*Department of Microbiology,

School of Medicine Gunma University, Maebashi, Japan

(Received February 4, 1974)

\section{References}

1) O'hara, K.; M. Kono \& S. Mitsuhashi: Enzymatic inactivation of a new aminoglycoside antibiotic, sisomicin, by resistant strains of Pseudomonas aeruginosa. Antimicr. Agents \& Chemoth. (in press)

2) Lowry, O. H.; N. J. Rosebrough, A. L. Farr \& R. J. Randall: Protein measurement with the Folin phenol reagent. J. Biol. Chem. 193: $265 \sim 275,1951$

3) Umezawa, H.; M. Okanishi, R. Utahara, K. MAEDA \& S. Kondo: Isolation and structure of kanamycin inactivated by a cell-free system of kanamycin inactivated by a cell free system of kanamycin-resistant $E$. coli. J. Antibiotics, Ser. A 20: 136 141, 1967

4) Daniels, P. J. L.; M. Kugelman, A.K. MalLams, R. W. TKach, H. F. Vernay, J. WeinStein \& A. Yehaskel: Mass spectral studies on aminocyclitol antibiotics. Chem. Commun. 1971: 1629 1631, 1971

5) Cooper, D. J.; M. D. Yudis, R. D. Guthrie \& A. M. PrIOR: The gentamicin antibiotics. I. Structure and absolute stereochemistry of methyl garosaminide. J. Chem. Soc. (C) 1971: 960 963, 1971

6) Cooper, D. J.; M. D. Yudis, H. M. MarigLiano \& T. Traubeu: The gentamicin antibiotics. II. Separation and degradation of the gentamicin $\mathrm{C}$ components. The purpurosamines, a new class of naturally occuring 2, 6-diaminomonosaccharides. J. Chem. Soc. (C) 1971: 2876 2879, 1971

7) Cooper, D. J.; P. J. L. Daniels, M. D. Yudis, H. M. Marigliano, R. D. Guthrie \& S. T. K. 
Bukhari: The gentamicin $\mathrm{C}$ antibiotics. III. The gross structures of the gentamicin C components. J. Chem. Soc. (C) 1971: 3126 3129, 1971

8) Inouye, S.: Mass spectra of N-salicylidene aminosugars. Chem. Pharm. Bull. 20: 2320 2330, 1972
9) Yamamoto, H.; M. Yagisawa, H. NagaNAWA, S. Kondo, T. TAKeuchi \& H. UmeZAWA: Kanamycin $6^{\prime}$-acetate and ribostamycin 6'-acetate, enzymatically inactivated products by Pseudomonas aeruginosa. J. Antibiotics 25: 746 747, 1972 